\title{
Risk factors for Salmonella spp in Portuguese breeding pigs using a multilevel analysis
}

\author{
C. Correia-Gomes ${ }^{\mathrm{a}, \mathrm{b}, *}$, D. Mendonça ${ }^{\mathrm{a}, \mathrm{b}}$, M. Vieira-Pinto ${ }^{\mathrm{c}}, \mathrm{J}$. Niza-Ribeiro ${ }^{\mathrm{a}, \mathrm{b}}$ \\ a Instituto de Ciências Biomédicas Abel Salazar (ICBAS), Universidade do Porto, Largo Prof. Abel Salazar, 2, 4099-003 Porto, Portugal \\ b Instituto de Saúde Pública da Universidade do Porto (ISPUP), Universidade do Porto, Rua das Taipas, 135, 4050-600 Porto, Portugal \\ c Departamento de Ciências Veterinárias, Universidade de Trás-os-Montes e Alto Douro (UTAD), Edif. Clínicas Veterinária, Quinta dos Prados, Apartado 1013, \\ 5001-801 Vila Real, Portugal
}

\section{A R T I C L E I N F O}

\section{Article history:}

Received 30 September 2011

Received in revised form 24 July 2012

Accepted 29 July 2012

\section{Keywords:}

Salmonella spp

Multilevel analysis

Risk factors

Pigs

Logistic regression

\begin{abstract}
A B S T R A C T
Salmonella is the second most frequent cause of foodborne illness in the European Union (EU), so EU enforced legislation to achieve a reduction in Salmonella prevalence in the swine sector. To set the reduction target each country carried out a baseline survey to estimate Salmonella prevalence. The aim of our study was to identify risk factors for the presence of Salmonella in breeding pigs based on the data of the Baseline Study for Salmonella in Breeding Pigs in Portugal. In total, 1670 pen fecal samples from 167 herds were tested by culture and 170 samples tested positive. Along with the collection of the samples a survey was applied to collect information about the herd management and potential risk factors. Multilevel analysis was applied to the data using generalized linear mixed models and a logit link function. The outcome variable was the presence/absence of Salmonella in the pen fecal samples. The first level was assigned to the pen fecal samples and the second level to the herds. The results showed significant associations between Salmonella occurrence and the factors $(p<0.05)$ : maternity pens versus mating pens ( $\mathrm{OR}=0.39,95 \% \mathrm{CI}: 0.24-0.63$ ), feed from external or mixed source versus home source ( $\mathrm{OR}=2.81,95 \% \mathrm{Cl}: 1.19-6.61)$, more than 10 animals per pen versus 10 animals per pen $(\mathrm{OR}=2.02,95 \% \mathrm{CI}$ : $1.19-3.43)$, North Region versus Alentejo Region $(\mathrm{OR}=3.86,95 \% \mathrm{CI}$ : $1.08-13.75)$, rodents control $(\mathrm{OR}=0.23$, $95 \%$ CI: $0.090-0.59$ ), more than $90 \%$ of boars homebred or no boars versus more than $90 \%$ of boars from an external source $(\mathrm{OR}=0.54,95 \% \mathrm{CI}$ : 0.3-0.97), semen from another herd versus semen from insemination centers ( $\mathrm{OR}=4.47,95 \% \mathrm{CI}$ : $1.38-14.43)$ and herds with a size of 170 or more sows ( $\mathrm{OR}=1.82,95 \% \mathrm{CI}: 1.04-3.19)$. This study offers very relevant information for both the Portuguese veterinary authorities and the pig farmers currently developing control programmes for Salmonella. This is the first study providing evidence for semen and boars source as risk factors for Salmonella in breeding pigs.
\end{abstract}

(c) 2012 Elsevier B.V. All rights reserved.

\section{Introduction}

Salmonella has been reported as the second most frequent cause of foodborne illness in the European Union (EU) in the past ten years (EFSA, 2010). The contribution

\footnotetext{
* Corresponding author at: Epidemiology Research Unit - SAC, Drummondhill, Stratherrick Road, Inverness, IV2 4JZ, UK. Tel.: +441463 717832.

E-mail addresses: cgomes@icbas.up.pt, carlasofiagomes@gmail.com (C. Correia-Gomes).
}

of pork products to the total burden of human salmonellosis cases varies between countries but it is estimated to be around 10\% (Pires et al., 2010). The EU Regulation (EU Regulation No 2160/2003) imposes to the Member States (MS) implementation of a control programme to reduce the prevalence in food production species including pigs. To set the reduction target each MS carried out baseline surveys to estimate the Salmonella spp. prevalence in some food production animals. The objective of the surveys was to obtain comparable data for all MS through harmonized sampling and testing schemes. In pigs the baseline study 
was done at abattoir level (collection of lymph nodes of pigs slaughtered) and at herd level (collection of pen fecal samples of breeding pigs). These cross-sectional studies also collected information regarding herd management practices and potential risk factors linked to this agent. After the specification of the reduction target each MS will have the responsibility to establish an effective national control programme adjusted for the country-specific characteristics, such as the risk factors, the disease prevalence and the financial implications for stakeholders.

It was expected that the baseline surveys supplied enough data to enable the identification and quantification of potential risk factors to be used in the development of programmes and procedures that reduces Salmonella shedding in pig herds economically and effectively. It is important that this information is available before Salmonella reduction programmes are implemented at the herd level to enable farmers to make informed choices, enhance public health and avoid unnecessary costs (Bahnson et al., 2006).

Some of the known risk factors already identified were linked to: (1) biosecurity measures (Baptista et al., 2010) such as potential biological vectors (as rodents) (Letellier et al., 1999; Meerburg and Kijlstra, 2007; Skov et al., 2008), hygiene of hands, equipment and facilities (Lo Fo Wong et al., 2004), purchase of animals from different suppliers (Lo Fo Wong et al., 2004), (2) herd management, such as herd size (Poljak et al., 2008), batch production system (Funk and Gebreyes, 2004), housing - type of floor (partial slatted floor) (Nollet et al., 2004; Rossel et al., 2006), type of pen separations (Lo Fo Wong et al., 2004), (3) feeding practices such as dry feed (Bahnson et al., 2006), purchase of feed (Benschop et al., 2008), adding organic acids to feed (Funk and Gebreyes, 2004), (4) the use of antibiotics (Beloeil et al., 2007; Funk et al., 2007), parasite infestations (van der Wolf et al., 2001; Beloeil et al., 2004), and health status of the herd (Funk and Gebreyes, 2004) among others (Fosse et al., 2009).

The data used in the present study were collected as part of the Baseline Survey on the Prevalence of Salmonella in Breeding Pigs in Portugal. The aim of the study was to identify risk factors for the presence of Salmonella in herds with breeding pigs.

\section{Materials and methods}

\subsection{Sampling and samples collection and analysis}

The data used in this study were transferred to the authors by the Portuguese Veterinary Authorities (PVA) and they are derived from the baseline study for Salmonella in Breeding Pigs in Portugal. This study was carried out by the PVA in the context of the Commission Decision $2008 / 55 / E C$. The authors were not involved in the baseline study and the data collection methodology described below is of the entire responsibility of the PVA.

The sampling frame, the diagnostic testing methods, the sample collection procedures and the timelines of the baseline study for Salmonella in Breeding Pigs were specified in the Commission Decision 2008/55/EC.
The target population was the holdings constituting at least $80 \%$ of the breeding pig population in the MS.

In Portugal, the sampling frame was organized by the PVA. These holdings were stratified by the Regions of the National Veterinary Services structure. There are currently five regions NUT II based in the Continental Portugal. In the sampling frame there were 4522 herds with a total of $1,827,533$ pigs, of which 204,584 were breeding pigs. In each region, herds with 50 or more breeding pigs were included. The sampling frame used in this study contained $87 \%$ of the total number of pigs reported in 2007 in Portugal. The required sample size was estimated based on an expected prevalence of $50 \%$, a desired confidence level of $95 \%$, an accuracy of $7.5 \%$, then applied a finite population correction factor, with an increase of $10 \%$ for each group (breeding and production holdings), to account for non-response, as specified by the Commission Decision 2008/55/EC Annex I. The sample size used by PVA was 174 swine herds. The choice of the herds to sample was random and proportional to the region, to take in consideration the difference in the number of herds in each region. The samples were collected between November 2008 and January 2009 by the herd veterinarian. Pooled fecal samples from 10 pens were collected in each herd. The pens were proportionally allocated to represent the number of breeding pigs in the different stages of production. The collection and composition of each pool was performed following the guidelines outlined in the Commission Decision 2008/55/EC. At least 10 individual breeding pigs had to contribute to one fecal pool. This procedure was estimated to provide $95 \%$ certainty of detecting at least one positive sample in a herd, if the true prevalence of infected pigs in the population was $10 \%$ (Anonymous, 2007). Before the sample collection the PVA conducted clarification meetings with all herd veterinarians involved in the study. The fecal samples were sent to the laboratory for microbiological detection of Salmonella according to the procedure defined by Annex D of ISO 6579. Each Salmonella isolate was serotyped in the National Reference Laboratory for Salmonella according to Kaulfmann-White scheme. The sensitivity of this culture method is around $80 \%$ and the specificity is $100 \%$ (Hoorfar and Mortensen, 2000; Arnold et al., 2005).

\subsection{Data collection}

Information about herd management and potential risk factors was collected using a questionnaire along with the collection of the fecal samples.

At herd level, the variables of the following theme categories were included: identification of the region of origin, the categorization of the holding production type (three variables), quantity and types of animals present (five variables), biosecurity measures and animal purchasing policy (eight variables). For detailed description of these variables see Table 1.

At pen level, the variables intended to characterise the type of housing (two variables), the number and type of animals in the pen (four variables), the clinical heath of pen (two variables); the floor type, the type of sanitary measures adopted in the holding before new breeding pigs 
Table 1

Herd variables distribution and univariable analyses to Salmonella spp. using data from the Baseline Survey on the Prevalence of Salmonella in Breeding Pigs in Portugal.

\begin{tabular}{|c|c|c|c|c|}
\hline \multirow[t]{2}{*}{ Variables } & \multirow[t]{2}{*}{ Herds with $\geq 1$ positive pen sample } & \multirow[t]{2}{*}{ Herds with no positive pen sample } & \multicolumn{2}{|c|}{ Univariable analyses } \\
\hline & & & OR estimate & $p$-Value \\
\hline \multicolumn{5}{|l|}{ System type } \\
\hline Outdoor & 1 & 2 & - & \\
\hline Indoor & 64 & 75 & 2.72 & 0.41 \\
\hline Missing cases & 11 & 14 & & \\
\hline \multicolumn{5}{|l|}{ Herd type } \\
\hline Selection and multiplication unit & 15 & 18 & - & \\
\hline Production unit & 61 & 72 & 0.87 & 0.68 \\
\hline \multicolumn{5}{|l|}{ Region of the herd } \\
\hline Alentejo & 11 & 14 & - & \\
\hline Centre & 17 & 15 & 1.63 & 0.31 \\
\hline Lisbon and Tagus Valley & 42 & 58 & 0.96 & 0.93 \\
\hline North & 6 & 4 & 2.72 & 0.11 \\
\hline \multicolumn{5}{|l|}{ Production type } \\
\hline Farrow-to-weaners & 12 & 7 & - & \\
\hline Farrow-to-growers & 10 & 17 & 0.40 & 0.20 \\
\hline Farrow-to-finish & 39 & 49 & 0.58 & 0.27 \\
\hline Missing cases & 15 & 18 & & \\
\hline \multicolumn{5}{|l|}{ Number of boars } \\
\hline$<3$ & 31 & 45 & - & \\
\hline$\geq 3$ & 45 & 46 & 1.80 & 0.03 \\
\hline \multicolumn{5}{|l|}{ Number of sows } \\
\hline$<170$ & 33 & 50 & - & \\
\hline$\geq 170$ & 43 & 41 & 1.53 & 0.13 \\
\hline \multicolumn{5}{|l|}{ Number of gilts } \\
\hline$<22$ & 32 & 46 & - & \\
\hline$\geq 22$ & 44 & 45 & 1.45 & 0.18 \\
\hline \multicolumn{5}{|l|}{ Total number of breeding pigs } \\
\hline$<203$ & 33 & 50 & - & \\
\hline$\geq 203$ & 43 & 41 & 1.53 & 0.13 \\
\hline Number of finishers pigs/herd & & & & \\
\hline$<100$ & 8 & 19 & - & \\
\hline$\geq 100$ & 67 & 71 & 1.98 & 0.09 \\
\hline Missing cases & 1 & 1 & & \\
\hline Management of breeding sows & & & & \\
\hline More than $90 \%$ purchased & 25 & 28 & - & \\
\hline$>90 \%$ homebred & 38 & 54 & 0.83 & 0.55 \\
\hline 10-90\% homebred & 13 & 9 & 1.62 & 0.27 \\
\hline Management of breeding boars & & & & \\
\hline More than $90 \%$ purchased & 42 & 28 & - & \\
\hline Without boars or $>90 \%$ homebred & 26 & 53 & 0.40 & $<0.01$ \\
\hline 10-90\% purchased or homebred & 8 & 10 & 0.77 & 0.55 \\
\hline Source of replacement pigs & & & & \\
\hline All homebred & 23 & 41 & - & \\
\hline Others sources & 52 & 50 & 1.56 & 0.13 \\
\hline Missing cases & 1 & 0 & & \\
\hline Source of semen & & & & \\
\hline Insemination centre $-\mathrm{CI}$ & 18 & 34 & - & \\
\hline Own boar +CI & 40 & 43 & 2.09 & 0.02 \\
\hline Boar from another herd & 14 & 11 & 5.28 & $<0.01$ \\
\hline Missing cases & 4 & 3 & & \\
\hline Good herd replacement policy & & & & \\
\hline Yes & 60 & 60 & - & \\
\hline No & 16 & 31 & 1.76 & 0.08 \\
\hline Rodents control & & & & \\
\hline No & 9 & 17 & - & \\
\hline Yes & 67 & 74 & 0.49 & 0.08 \\
\hline Control of birds & & & & \\
\hline No & 20 & 15 & - & \\
\hline Yes & 56 & 76 & 1.45 & 0.27 \\
\hline Use of foot bath & & & & \\
\hline No & 22 & 31 & - & \\
\hline Yes & 54 & 60 & 0.77 & 0.38 \\
\hline Clothes for exclusive use in the herd & & & & \\
\hline Yes & 74 & 85 & - & \\
\hline No & 2 & 6 & 0.35 & 0.18 \\
\hline Good biosecurity measures & & & & \\
\hline Yes & 34 & 40 & - & \\
\hline No & 42 & 51 & 0.86 & 0.60 \\
\hline
\end{tabular}


Table 2

Pen variable distribution to Salmonella spp. and univariable analyses in pen fecal samples using data from the Baseline Survey on the Prevalence of Salmonella in Breeding Pigs in Portugal.

\begin{tabular}{|c|c|c|c|c|}
\hline \multirow[t]{2}{*}{ Variable } & \multirow[t]{2}{*}{ Positive pen samples } & \multirow[t]{2}{*}{ Negative pen samples } & \multicolumn{2}{|c|}{ Univariable analyses } \\
\hline & & & OR estimate & $p$-Value \\
\hline \multicolumn{5}{|l|}{ Number of animals per pen } \\
\hline$=10$ & 128 & 1284 & - & \\
\hline$>10$ & 42 & 216 & 2.60 & $<0.01$ \\
\hline \multicolumn{5}{|l|}{ The pen has direct access to outside } \\
\hline No & 122 & 1146 & - & \\
\hline Yes & 48 & 354 & 1.48 & 0.15 \\
\hline \multicolumn{5}{|l|}{ Individual pen } \\
\hline No & 29 & 306 & - & \\
\hline Yes & 139 & 1194 & 1.05 & 0.80 \\
\hline Missing cases & 2 & 0 & & \\
\hline \multicolumn{5}{|l|}{ Diarrhoea in the last 3 months } \\
\hline No & 163 & 1445 & - & \\
\hline Yes & 3 & 33 & 1.44 & 0.57 \\
\hline Missing cases & 4 & 22 & & \\
\hline \multicolumn{5}{|l|}{ Age of the breeding sows } \\
\hline Only gilts or mixed age & 111 & 874 & - & \\
\hline Without gilts & 59 & 626 & 0.73 & 0.11 \\
\hline \multicolumn{5}{|l|}{ Sex of the breeding pigs } \\
\hline Only sows & 158 & 1430 & - & \\
\hline Boars or/and sows & 12 & 70 & 2.13 & 0.04 \\
\hline \multicolumn{5}{|l|}{ Breeding sector room } \\
\hline Mating & 31 & 219 & - & \\
\hline Gestation & 88 & 789 & 0.79 & 0.20 \\
\hline Mixture of animals of different sectors & 15 & 58 & 1.68 & 0.22 \\
\hline Maternity & 29 & 390 & 0.43 & $<0.01$ \\
\hline Replacement breeders & 7 & 44 & 0.83 & 0.64 \\
\hline \multicolumn{5}{|l|}{ Floor } \\
\hline Fully slatted & 14 & 137 & - & \\
\hline Others & 146 & 1353 & 0.96 & 0.89 \\
\hline \multicolumn{5}{|l|}{ Sanitary gap before new breeders in the pen } \\
\hline No & 107 & 874 & - & \\
\hline Yes & 63 & 626 & 1.77 & $<0.01$ \\
\hline \multicolumn{5}{|l|}{ Feed } \\
\hline Dry pellet & 34 & 229 & - & \\
\hline Dry non pellet & 133 & 1230 & 0.87 & 0.72 \\
\hline Wet & 3 & 41 & 0.32 & 0.23 \\
\hline \multicolumn{5}{|l|}{ Source of feed } \\
\hline Exclusively own & 16 & 199 & - & \\
\hline Purchased + mixture & 154 & 1301 & 1.52 & 0.33 \\
\hline \multicolumn{5}{|c|}{ Potential Salmonella control substances added to water } \\
\hline No & 149 & 1291 & - & \\
\hline Yes & 21 & 209 & 1.08 & 0.84 \\
\hline \multicolumn{5}{|c|}{ Use of antibiotics in the last 4 weeks in breeders } \\
\hline No & 148 & 1229 & - & \\
\hline Yes & 22 & 271 & 0.50 & 0.01 \\
\hline \multicolumn{5}{|l|}{ Approach used to collect the pooled sample } \\
\hline Individual pinches & 158 & 1379 & - & \\
\hline Swab & 12 & 121 & 0.49 & 0.03 \\
\hline
\end{tabular}

entered the pen were also characterized along with feeding management policy (three variables). The method used to collect the fecal samples, swab or individual pinches, was also recorded in the questionnaire. For detailed description of these variables see Table 2 .

\subsection{Statistical analysis}

To perform the present study the authors created a database. After entering the data in the database, the variables and their categories were recoded or aggregated to fewer categories as necessary to avoid sparse data problems, and two new binary variables were created: Good herd replacement policy and Good biosecurity measures.
The variable "Good herd replacement policy" groups the questions about management and source of replacement breeding pigs; it was coded as 'Yes' if more than $90 \%$ of the breeding sows and boars were homebred or without boars, and if the semen did not come from another herd, and as 'No' otherwise. The variable "Good biosecurity measures" groups the questions about biosecurity measures was coded as 'Yes' for herds which controlled rodents and birds access to barns, had a foot bath and had clothes exclusively for use in the herd, and as 'No' otherwise. Tables 1 and 2 summarise the variables.

For continuous variables basic description statistics including mean, median and percentiles were derived (Table 3). These results were used to give information on how to categorise the continuous variables. 
Table 3

Descriptive measures of continuous variables for the presence of Salmonella spp in pen fecal samples using data from the Baseline Survey on the Prevalence of Salmonella in Breeding Pigs in Portugal.

\begin{tabular}{|c|c|c|c|c|c|c|c|}
\hline Variable & Presence of Salmonella & Mean & Minimum & Percentile 25 & Median & Percentile 75 & Maximum \\
\hline \multirow[t]{2}{*}{ Number of boars } & Yes & 4.4 & 0 & 2 & 3 & 5 & 28 \\
\hline & No & 3.5 & 0 & 2 & 3 & 4 & 18 \\
\hline \multirow{2}{*}{ Number of sows } & Yes & 245.2 & 8 & 100 & 200 & 325 & 1077 \\
\hline & No & 210.9 & 35 & 90 & 136 & 250 & 1074 \\
\hline \multirow[t]{2}{*}{ Number of gilts } & Yes & 35.6 & 0 & 15 & 25.5 & 40 & 187 \\
\hline & No & 32.7 & 0 & 10 & 21 & 38 & 300 \\
\hline \multirow[t]{2}{*}{ Number of reproductive pigs } & Yes & 285.2 & 43 & 130 & 224.5 & 370 & 1186 \\
\hline & No & 248.2 & 41 & 103 & 182 & 293 & 1214 \\
\hline \multirow[t]{2}{*}{ Number of animals in the pen } & Yes & 12.8 & 10 & 10 & 10 & 10 & 90 \\
\hline & No & 11.5 & 10 & 10 & 10 & 10 & 130 \\
\hline
\end{tabular}

To identify the risk factors for the presence of Salmonella in breeding pigs, the response variable was the presence of Salmonella in each fecal sample and it was classified as positive when Salmonella was detected and negative otherwise. As the data follow a multilevel structure, pen fecal samples (first level) nested within swine herds (second level), a two level hierarchical logistic regression model was fitted using the framework of generalized linear mixed model (GLMM) methods implemented in the glmmPQL procedure of package MASS (Venables and Ripley, 2002) of R free software (CRAN project, www.R-project.org). The fixed effects were estimated by a second order penalized quasi-likelihood (PQL) using the Breslow and Clayton's algorithm (Breslow and Clayton, 1993). The algorithm iterates between a series of iterated weighted least squares iterations to update the fixed effects and a single Fisher scoring iteration to update the standard deviation of the random effects.

The data were modeled in the following way:

$Y= \begin{cases}0 & \text { (no Salmonella) } \\ 1 & \text { (Salmonella) }\end{cases}$

where $Y$ is the response variable.

$\operatorname{Pr}(Y)=p_{i h}, i=1, \ldots, 1670$ and $h=1, \ldots, 167$

The generic model used:

$$
\begin{array}{rl}
\log i t\left(p_{i h}\right)= & a+\beta_{k} \text { herd } \text { variables }_{h}+\beta_{k} \text { pen variables }_{h i} \\
& +\beta_{k} \text { herd } \text { variables }_{h} * \text { herd } \text { variables }_{h} \\
& +\beta_{k} \text { pen variables } \\
h i & * \text { pen variables }_{h i} \\
& +\beta_{k} \text { herd } \text { variables }_{h} * \text { pen variables }_{h i}+b_{h}
\end{array}
$$

When modeling dichotomous data the lowest-level residual variance is not in the model equation because it is part of the specification of the error distribution (Hox, 2002; Goldstein, 2011). The second level random effect is given by $b_{h} \sim N\left(0, \sigma^{2}\right)$ where $\sigma^{2}$ is the variance of the random effects at herd level.

The logit link function was used to model the probability of occurrence of Salmonella. The random effects are in the form of a random intercept and this allows for the fact that the observations are nested in herds. Treating the herd effect as random, also allows for the fact that the number of herds (167) is a sample of all existing herds and not the whole population.

\subsection{Univariable analyses}

Candidate variables for the multivariable model were screened with univariable analysis. A relaxed significance level of $\alpha=0.15$ was used to select variables to enter in the multivariable model.

As the variables were all categorised, association between the independent variables were tested using a chi-square test. The existence of significant associations between the independent variables was tested before adding them into the final multivariable model. It was expected the existence of association between variables like "Good herd replacement" or "Good biosecurity measures" and the variables that were used to create them. When association between variables was present, it was allowed to enter in the multivariable model just one variable at each time. The selection between which candidate variable would be included into the final model was decided by testing both variables and selecting the one presenting the smallest $p$-value.

\subsection{Multivariable analysis}

Stepwise procedures were used to select the statistically significant variables to enter/remove in the final multivariable model. At each step, the independent variable not in the model that had the smallest $p$-value was entered, and variables already in the model were removed if their $p$ value became larger than the significance level of $\alpha=0.05$. The model was terminated when no more variables were eligible for inclusion or removal.

Two-way interaction between variables of the same level (herd or pen) and also cross-level interactions were analysed. Interactions between variables with biological meaning (e.g. source of semen and management of breeding boars, number of sows and number of animals per pen) were manually tested at both levels and retained if the $p<0.05$. Confounding was assessed through the examination of the changes in the magnitude of the coefficients and looking at their biological significance and the regression coefficients were converted to odds ratio (OR) and the respectively $95 \%$ OR confidence interval $(\mathrm{CI})$ were estimated. The relevance of the herd random effects was tested by looking at the variance estimate; the interpretation was that when this estimate it is close to zero it gives an indication that the herd effect does not contribute to the 
dispersion of the outcome variable and a simpler model (without random effects) could be chosen (Twisk, 2006).

\section{Results}

A total of 1670 fecal pen samples (level 1) belonging to 167 herds (level 2), that responded to the questionnaire, were tested. Among the samples tested 170 from 76 herds were positive to Salmonella. Salmonella Typhimurium, followed by Salmonella Rissen were the most frequent serotypes found in the positive samples.

In the 167 herds there were 33 breeding holdings (45.45\% had at least one sample positive to Salmonella, CI: $37.9-53.1 \%$ ) and 134 productions holdings ( $45.45 \%$ had at least one sample positive to Salmonella, CI: 28.5-62.4\%).

Tables 1 and 2 describe the different variables taking into consideration the presence of Salmonella in the pen fecal samples. Table 3 shows the descriptive statistics of the herd and pen continuous variables.

There was information missing in $15 \%$ of the herds for the variables system type and production type nevertheless these variables at univariable analyses did not meet the criterion to enter in the multivariable model.

The results of the univariable analyses are shown in Tables 1 and 2. The variables region of the herd, number of boars, number of sows, total number of breeding pigs, number of finishers pigs/herd, management of breeding boars, source of replacement pigs, source of semen, good herd replacement policy, rodents control, number of animals per pen, pens with access to outside, age of breeding sows, sex of the breeding pigs, breeding sector room, sanitary gap before new breeders in the pen, source of feed, use of antibiotics in the last 4 weeks in breeders and approach used to collect the pooled sample were selected to enter the multivariable model. Although the variable source of feed had a $p$ value higher than 0.15 in the univariable analysis, it was forced to enter in the multivariable model, because this variable has been described as a risk factor in several previous studies (Lo Fo Wong et al., 2004; Benschop et al., 2008). To avoid collinearity problems, the variables number of sows and number of boars rather than total number of breeding pigs, and the variables management of breeding boars and source of semen rather than Good herd replacement policy were selected to enter the multivariable model. No significant association was found between the remaining variables. In the final multivariable model just the variables with $p<0.05$ were selected to remain (Table 4). The OR for each variable is adjusted for the remaining variables in the model. There was not any significant interaction between the variables that were kept in the final multivariable model.

The significant results were: (1) region of the herd: samples from herds in the North Region had higher odds of being positive to Salmonella than samples from herds in the Alentejo Region; (2) rodents control: samples from herds with rodents control showed lower odds of being positive; (3) number of sows: herds with 170 and more sows presented higher odds of being infected; (4) source of semen: use of semen from another herd was a risk factor; (5) management of breeding boars: herds without boars or with $90 \%$ homebred boars showed lower odds of being positive; (6) breeding sector room: samples collected by the PVA at the maternity pens had lower odds of being positive than samples from mating pens; (7) source of feed: the samples where the source of feed was not exclusively from own herd had higher odds of being positive; and (8) number of animals per pen: having more than 10 animals in the pen showed higher odds of being positive. The variance of the random effect $\left(\sigma^{2}\right)$ at herd level was estimated to be 1.5 which given the small standard error associated was interpreted as the variance being different from zero (Table 4).

\section{Discussion}

In this study a representative sample of the herds with breeding pigs in Portugal was used. The herds sampled were obtained using a sampling frame assembled by the PVA. The sample was representative of the country and took into consideration the different number of herds per region. The herds were randomly allocated to the study. The risk factors were assessed using data from a questionnaire filled by the herd veterinarian which were also responsible for the collection of the feces samples. The majority of the questions were closed; only a few were semi-open or open, such as the type and source of feed, soil type, the use of antimicrobial substances added to water or feed, and which antibiotic was used in breeders in the last four weeks before sample collection. To minimize the bias that could be introduced by having different people collecting the data, clarification meetings coordinated by the PVA were entertained with the herds veterinarians before the sample collection took place and the questionnaire had clear filling out instructions attached. Our judgment is that the validity of the data is quite robust given the care taken in the collection of the information and in the Salmonella isolation procedure.

Sampling the pen as a unit allows overcoming the problem of individual low sensitivity of the fecal culture, partly due to the intermittent shedding that infected pigs show. After the study conducted by Arnold and Cook (2009) it was demonstrated that the use of pooled fecal samples collected according to guidelines outlined in Commission Decision 2008/55/EC increases the likelihood of detecting pens where there is at least one pig infected with Salmonella. Therefore the overall sensitivity and ability to detect infected pens was increased in this study. As the specificity is $100 \%$ we are sure about the presence of Salmonella in positive samples.

Concerning the statistical data analysis it was decided to use a multilevel model because of the "natural" structure of data: the pen fecal samples (level 1 ) were nested in herds (level 2). Using this model the data structure is taken into consideration and the relationship of all variables, measured at herd or pen level is preserved and accounted for. This model also increases the power of the analysis and at the same time evaluates the variability associated with herd. The random effects are applied to models when is believed that the variance at group level is higher than zero. The variance $\left(\sigma^{2}\right)$ of the random effect at herd level $\left(b_{h}\right)$ was estimated to be 1.5 , which means that a relatively large variability in the data was due to herd effect and the 
Table 4

Final multivariable model for the presence of Salmonella spp in pen fecal samples using the data from the Baseline Survey on the Prevalence of Salmonella in Breeding Pigs in Portugal (in bold $p<0.05$ ).

\begin{tabular}{|c|c|c|c|}
\hline \multirow[t]{3}{*}{ Variable } & \multicolumn{3}{|c|}{ Multivariable analysis } \\
\hline & \multicolumn{3}{|l|}{ OR } \\
\hline & Estimate & $95 \% \mathrm{CI}$ & $p$-Value \\
\hline \multicolumn{4}{|l|}{ Herd variables } \\
\hline \multicolumn{4}{|l|}{ Region of the herd } \\
\hline Alentejo & 1.00 & & \\
\hline Centre & 1.97 & $0.75-5.22$ & 0.17 \\
\hline Lisbon and Tagus Valley & 1.40 & $0.61-3.20$ & 0.43 \\
\hline North & 3.86 & $1.08-13.75$ & 0.04 \\
\hline \multicolumn{4}{|l|}{ Number of sows } \\
\hline$<170$ & 1.00 & & \\
\hline$\geq 170$ & 1.82 & $1.04-3.19$ & 0.04 \\
\hline \multicolumn{4}{|l|}{ Management of breeding boars } \\
\hline More than $90 \%$ purchased & 1.00 & & \\
\hline Without boars or $>90 \%$ homebred & 0.54 & $0.30-0.97$ & 0.04 \\
\hline 10-90\% purchased or homebred & 0.93 & $0.38-2.30$ & 0.88 \\
\hline \multicolumn{4}{|l|}{ Source of semen } \\
\hline Insemination centre $-\mathrm{CI}$ & 1.00 & & \\
\hline Own boar $+\mathrm{CI}$ & 1.84 & $0.97-3.46$ & 0.06 \\
\hline Boar from another herd & 4.47 & $1.38-14.43$ & 0.01 \\
\hline \multicolumn{4}{|l|}{ Rodents control } \\
\hline No & 1.00 & & \\
\hline Yes & 0.23 & $0.09-0.59$ & $<0.01$ \\
\hline \multicolumn{4}{|l|}{ Sample variables } \\
\hline \multicolumn{4}{|l|}{ Number of animals per pen } \\
\hline$=10$ & 1.00 & & \\
\hline$\geq 10$ & 2.02 & $1.19-3.43$ & $<0.01$ \\
\hline \multicolumn{4}{|l|}{ Breeding sector room } \\
\hline Mating & 1.00 & & \\
\hline Gestation & 0.78 & $0.53-1.15$ & 0.21 \\
\hline Mixture of animals of different sectors & 1.55 & $0.62-3.89$ & 0.35 \\
\hline Maternity & 0.39 & $0.24-0.63$ & $<0.01$ \\
\hline Replacement breeders & 0.81 & $0.26-1.81$ & 0.61 \\
\hline \multicolumn{4}{|l|}{ Source of feed } \\
\hline Exclusively own & 1.00 & & \\
\hline Not exclusively own & 2.81 & $1.19-6.61$ & 0.02 \\
\hline Random effects ${ }^{\mathrm{a}}$ & Variance & Standard deviation & \\
\hline At herd level & 1.50 & 0.75 & \\
\hline
\end{tabular}

OR: odds ratio, $\mathrm{CI}$ : confidence interval for odds ratio.

a Variance at pen fecal level constrained to be 1 (binomial variance).

use of multilevel model was an adequate choice. The multilevel methodology provides a solid approach and could be considered when the data follows a multilevel structure to allow the incorporation of group effect.

In the final multivariable model several significant risk associations were found. The pens where the feed was purchased had a higher risk of being Salmonella positive, similar to what has been found in another study (Benschop et al., 2008). Feed is a source of potential transmission of Salmonella and this hazard should be controlled by feed producers. The role of rodents in the transmission of this agent was also highlighted in other studies (Meerburg and Kijlstra, 2007; Skov et al., 2008). A protective association for the herds that control rodents was also found in this study. Rodents are biological vectors of Salmonella and if not controlled could play an important role in the transmission of the agent within herds and between nearby herds. The number of sows in a herd is a measure of the size of the herd and in this study herds with 170 and more sows had higher risk of being positive. This type of association was already found in the literature for finishers herds (Poljak et al., 2008) and it is mainly associated with practices of mixture of pigs which happens commonly in big herds. The mating pens had a higher risk when compared to maternity pens. This result is similar to the result found in a longitudinal study (Nollet et al., 2005) where it was detected more sows shedding Salmonella at mating than in the other sectors, and it was justified by the hormonal changes in the sow at mating which contribute to a higher shedding of the bacteria. The results concerning the region (North with higher risk than the South) was surprising and need further investigation with spatial analysis to see if factors not collected in this study may influence this result. The use of semen from another herd was a risk factor when compared to the use of semen from insemination centres, where the quality and safety of semen is controlled and tested. This association was not previously found in literature probably because in the majority of the countries the semen comes from insemination centres. This risk factor highlights the need to change this practice in Portugal. The management of breeding boars (used either for heat detection and or for breeding purposes) was also a risk factor and using 
homebred boars was safer than using purchased boars. This could be explained because only $20 \%$ of the herds with more than $90 \%$ purchased boars used semen from insemination centres, while in the herds without boars or with more than $90 \%$ homebred around $48 \%$ used semen from insemination centres. The fact that semen and boars are controlled practices in many countries preclude the assessment of these variables as risk factors when statistical analyses are carried out using datasets from these countries. However it is important to keep in mind that controlling these sources is of high importance in every system to effectively prevent Salmonella new infection of the herd.

So far in Portugal only a few studies about herd risk factors have been done (Baptista et al., 2010), therefore our results are pertinent and useful. Furthermore as the pig sector in Portugal has a similar structure to those in France, Ireland and Italy among other countries (VLA-DTU-RIVM, 2010) these results may contribute to the knowledge of risk factors in these countries.

\section{Conclusion}

The risks highlighted in this study are epidemiologically and biologically consistent and they are representative of the breeding pigs system currently used in Portugal. It is noticeable the identification of risks associated with semen and boars purchasing: this reinforces that attention should be paid to these factors when conceiving herd biosecurity programmes; also noticeable and important is the fact that these risk factors have not been highlighted before. Our findings are of high relevance to the Portuguese Veterinary Authorities and also to pig farmers which are currently facing the lack of country adapted information to elaborate the control programmes for Salmonella. To achieve prevalence reduction, control programmes have to be implemented and the measures of the future control programmes should be cost-effective and adapted to country features. In this context this study gives valuable information to be incorporated in the near future control programme for Salmonella in breeding pigs in Portugal.

\section{Acknowledgments}

We would like to thank FCT for the PhD scholarship (SFRH/BD/40932/2007) and the Portuguese official veterinary authority (DGV) for supplying the data from the Baseline Survey on the Prevalence of Salmonella in Breeding Pigs.

\section{References}

Anonymous, 2007. Report of the Task Force on Zoonoses Data Collection on a proposal for technical specifications for a baseline survey on the prevalence of Salmonella in breeding pigs. EFSA J. 99, 1-28.

Arnold, M.E., Cook, A., Davies, R., 2005. A modelling approach to estimate the sensitivity of pooled faecal samples for isolation of Salmonella in pigs. J. R. Soc. Interface 2, 365-372.

Arnold, M.E., Cook, A.J., 2009. Estimation of sample sizes for pooled faecal sampling for detection of Salmonella in pigs. Epidemiol. Infect., 1-8.

Bahnson, P.B., Fedorka-Cray, P.J., Ladely, S.R., Mateus-Pinilla, N.E., 2006. Herd-level risk factors for Salmonella enterica subsp. enterica in U.S. market pigs. Prev. Vet. Med. 76, 249-262.
Baptista, F.M., Alban, L., Nielsen, L.R., Domingos, I., Pomba, C., Almeida, V., 2010. Use of herd information for predicting Salmonella status in pig herds. Zoonoses Public Health 57, 49-59.

Beloeil, P.A., Chauvin, C., Proux, K., Fablet, C., Madec, F., Alioum, A., 2007. Risk factors for Salmonella seroconversion of fattening pigs in farrowto-finish herds. Vet. Res. 38, 835-848.

Beloeil, P.A., Fravalo, P., Fablet, C., Jolly, J.P., Eveno, E., Hascoet, Y., Chauvin, C., Salvat, G., Madec, F., 2004. Risk factors for Salmonella enterica subsp. enterica shedding by market-age pigs in French farrow-tofinish herds. Prev. Vet. Med. 63, 103-120.

Benschop, J., Stevenson, M.A., Dahl, J., French, N.P., 2008. Towards incorporating spatial risk analysis for Salmonella sero-positivity into the Danish swine surveillance programme. Prev. Vet. Med. 83, 347-359.

Breslow, N.E., Clayton, D.G., 1993. Approximate inference in generalized linear mixed models. JASA 88, 9-25.

EFSA, 2010. The community summary report on trends and sources of zoonoses and zoonotic agents and food-borne outbreaks in the European Union 2008. EFSA J. 1496, 288.

Fosse, J., Seegers, H., Magras, C., 2009. Prevalence and risk factors for bacterial food-borne zoonotic hazards in slaughter pigs: a review. Zoonoses Public Health 56, 429-454.

Funk, J., Gebreyes, W.A., 2004. Risk factors associated with Salmonella prevalence on swine farms. J. Swine Health Prod. 12, $246-251$

Funk, J., Wittum, T.E., LeJeune, J.T., Rajala-Schultz, P.J., Bowman, A., Mack, A., 2007. Evaluation of stocking density and subtherapeutic chlortetracycline on Salmonella enterica subsp enterica shedding in growing swine. Vet. Microbiol. 124, 202-208.

Goldstein, H., 2011. Multilevel Statistical Models. John Wiley \& Sons.

Hoorfar, J., Mortensen, A.V., 2000. Improved culture methods for isolation of Salmonella organisms from swine feces. Am. J. Vet. Res. 61, $1426-1429$.

Hox, J.J., 2002. Multilevel Analysis: Techniques and Applications. Lawrence Erlbaum Associates.

Letellier, A., Messier, S., Paré, J., Ménard, J., Quessy, S., 1999. Distribution of Salmonella in swine herds in Québec. Vet. Microbiol. 67, 299-306.

Lo Fo Wong, D.M., Dahl, J., Stege, H., van der Wolf, P.J., Leontides, L., von Altrock, A., Thorberg, B.M., 2004. Herd-level risk factors for subclinical Salmonella infection in European finishing-pig herds. Prev. Vet. Med. $62,253-266$

Meerburg, B.G., Kijlstra, A., 2007. Role of rodents in transmission of Salmonella and Campylobacter. J. Sci. Food Agric. 87, 2774-2781.

Nollet, N., Houf, K., Dewulf, J., De Kruif, A., De Zutter, L., Maes, D., 2005. Salmonella in sows: a longitudinal study in farrow-to-finish pig herds. Vet. Res. 36, 645-656.

Nollet, N., Maes, D., De Zutter, L., Duchateau, L., Houf, K., Huysmans, K., Imberechts, H., Geers, R., de Kruif, A., Van Hoof, J., 2004. Risk factors for the herd-level bacteriologic prevalence of Salmonella in Belgian slaughter pigs. Prev. Vet. Med. 65, 63-75.

Pires, S.M., Vigre, H., Makela, P., Hald, T., 2010. Using outbreak data for source attribution of human salmonellosis and campylobacteriosis in Europe. Foodborne Pathog. Dis. 7, 1351-1361.

Poljak, Z., Dewey, C.E., Friendship, R.M., Martin, S.W., Christensen, J., 2008. Multilevel analysis of risk factors for Salmonella shedding in Ontario finishing pigs. Epidemiol. Infect. 136, 1388-1400.

Rossel, R., Rouillier, J., Beloeil, P.A., Chauvin, C., Basta, F., Crabos, J.P., TheauAudin, S., 2006. Salmonella en élevage de porcs du Sud-Ouest de la France: séroprévalence en fin d'engraissement et facteurs de risque associés. Journées de la Recherche Porcine 38, 371-378.

Skov, M.N., Madsen, J.J., Rahbek, C., Lodal, J., Jespersen, J.B., Jørgensen, J.C., Dietz, H.H., Chriél, M., Baggesen, D.L., 2008. Transmission of Salmonella between wildlife and meat-production animals in Denmark. J. Appl. Microbiol. 105, 1558-1568.

Twisk, J.W.R. (Ed.), 2006. Applied Multilevel Analysis - A Pratical Guide for Medical Researchers. Cambridge University Press, Cambridge.

van der Wolf, P.J., Wolbers, W.B., Elbers, A.R.W., van der Heijden, H.M.J.F., Koppen, J.M.C.C., Hunneman, W.A., van Schie, F.W., Tielen, M.J.M., 2001. Herd level husbandry factors associated with the serological Salmonella prevalence in finishing pig herds in The Netherlands. Vet. Microbiol. 78, 205-219.

Venables, W.N., Ripley, B.D., 2002. Modern Applied Statistics with S. Springer, New York.

VLA-DTU-RIVM, 2010. EFSA Quantitative Microbiological Risk Assessment on Salmonella in Slaughter and Breeder Pigs: Final Report. Question No EFSA-Q-2007-00245. Grant number CFP/EFSA/BIOHAZ/2007/01. Veterinary Laboratories Agency., p. 437. 